Military Technical College

Kobry El-Kobbah, Cairo, Egypt.

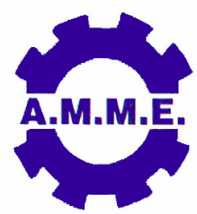

\title{
ANALYTICAL STUDY OF GAS UNIT GEOMETRICAL CHARACTERISTICS AND THEIR IMPACT ON THE MOMENTUM OF RECOLILING PARTS
}

\author{
M. S. Abo-Elkhair
}

\begin{abstract}
On handling the problem of automation in automatic weapons (AW), it is important to analyze the motion of these weapon mechanisms during their function cycle $[1,2]$. Many activities are performed during the backward motion of weapon mechanisms using the power of branching gases from what known as Gas Unit (GU). These activities starts with under-slide motion, unlocking, extraction of empty Cartridge Case (c.c.), backward motion against springs, ejection of empty c.c., and ending by loading of trigger at the extreme rear position. All these activities are performed in a reversed manner during the counter recoil track.
\end{abstract}

In this paper; the parameters affecting the momentum of branching gases have been extensively studied, the performance of the gas unit is converted to touchable figures in order to facilitate the evaluation. These evaluations are presented in forms of change in pressure of gases inside the GU, maximum velocity of recoil, and the displacement of recoiling parts until the pressure inside the gas unit reaches the atmospheric value $[7,8]$. The predicted results determine the weight of each parameter that affects the momentum of gases. Moreover, the affecting parameters of GU on the weapon performance during the function cycle may be considered on modifying the power of in-service weapons, or the newly designed generations

${ }^{*}$ Egyptian armed forces. 


\section{HISTORICAL PREVIEW ON REGULATION OF GASES IN FIREARMS}

Before the Russian scientist Michael Kalashnikov had started his work designing and producing his worldwide famous design of the Automatic rifle AK47, other investigators have been worked hardly in order to reach the different ways of automation [12, 3, 4]. In the following; samples of the worldwide patents in the field of gas regulation are introduced. These patents are concerned with the optimization of the use of produced gases from burning of propellant charge in driving the mechanisms of the firearms automatically.

In 1929; Frederick studied the arrangement developed by Browning (Feb. 1919) in his automatic weapon GU model; and he decided to simplify his constructional arrangement offering new features [2] simply characterized by:

i- Supplying a piston with three sealing stations as marked by the numbers 17,18 \& 19 in Fig. 1.

ii-Inserting a regulating plug with three different sized orifices that allow setting of gas regulator in 3 positions.

These positions are presented on Fig. 1 by marks $12-a, 12-b$, and 12-c each opening has different cross
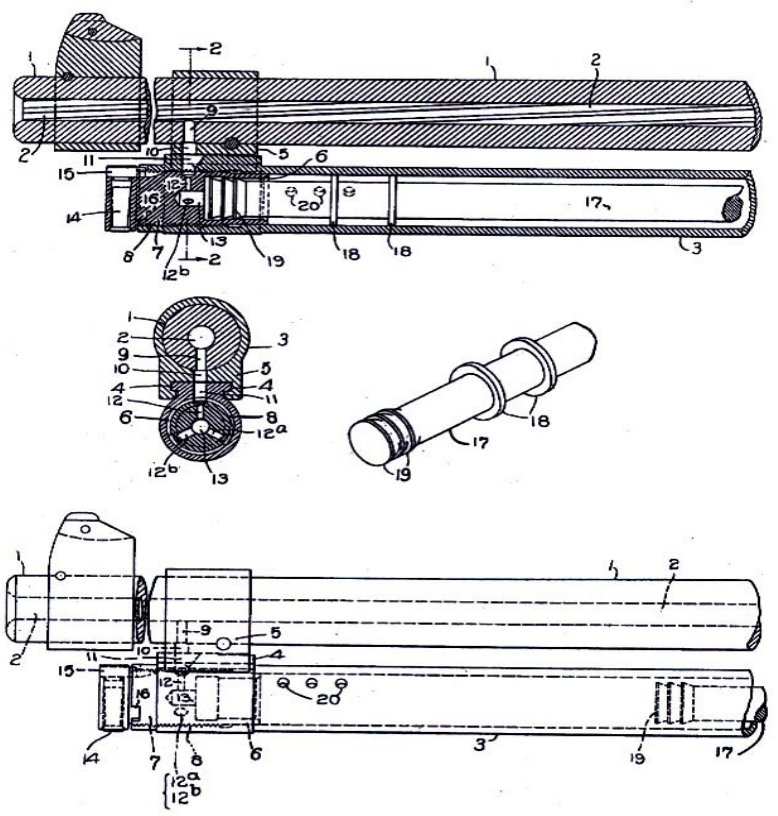

Fig.1. Frederick idea of GU regulator. sectional area of gas vent, these vents control the rate of fire or they may be adjusted in three stages having the life time of the automatic firearm.

In Fig. 2 of a gas regulator is simply the patent introduced by John Garand 1945; it allows a wide control over the initial volume of gas unit chamber. It allows the possibility of suppressing the effect of sudden increase in gases; especially when using different types of ammunitions in the same firearm. Such design considers the release of excessive flow of gases in a way similar to the function of relieve valves [3].

In 1949, Moore [4] introduced a new idea, this invention is related to the improvements in an automatic firearm, wherein the firing mechanism was operated by means of branching gases which are allowed to escape from the barrel (7) and acted upon a movable piston (5) and is directed impinging on the piston which in turn is regulated. The control of these produced gases in such a fire-arm was very desirable not only to allow for the fluctuation of the pressures of the escaping gases but also to eliminate in so far as possible the excessive effect of their sudden increase. 


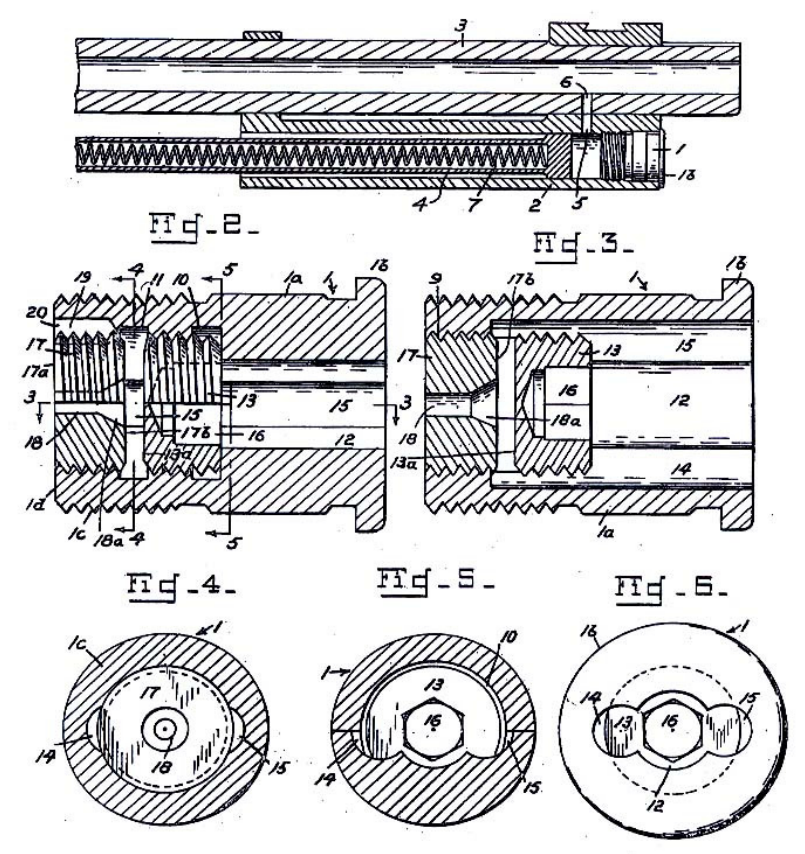

Fig. 2. Garand construction of gas unit regulator [3].

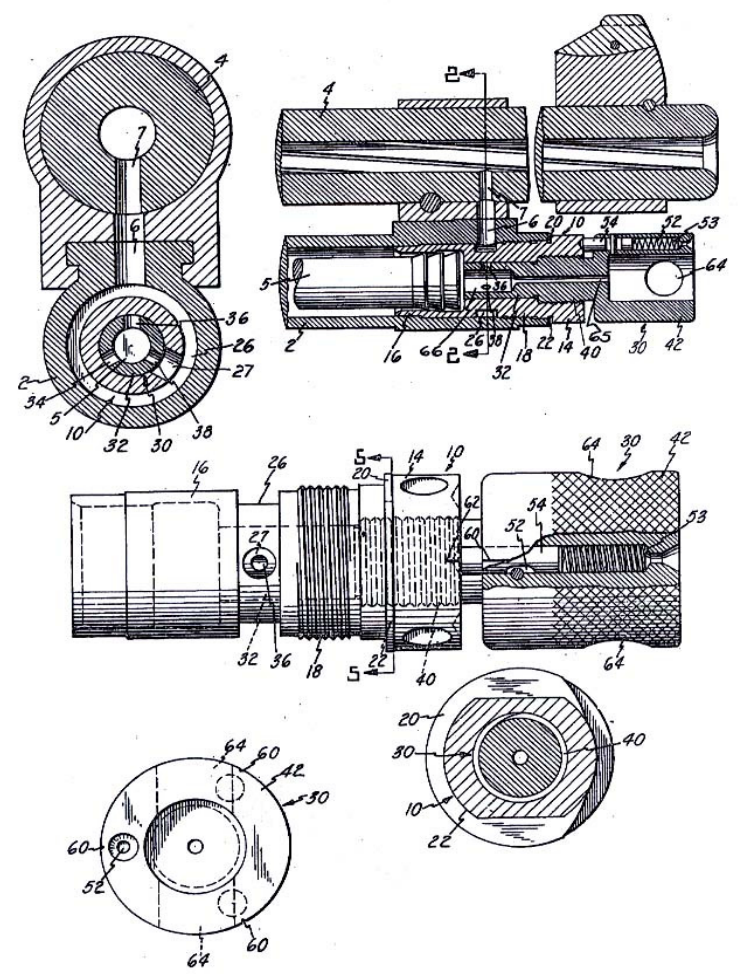

Fig.3. Moore construction of gas unit regulator [4].

Moore has introduced a complicated structure for gas unit regulators, in which gases branches from barrel bore through orifice at (part 7) after which regulation took place in a cylindrical perforated structure (part 56) which was fed by gases from a cavity (part26), and the main opening (part60) leading to 3 different gas vents. 


\section{REGULATION OF INTENSITY OF POWDER GASES IN THE CHAMBER}

Rather than other arrangements in automatic weapons with gas operated systems allow the wide control over the power of fire in AW through: changing the position of gas vent with respect to barrel bore, selecting the optimum values of the mass of recoiling parts, and finally enhancing the effect of heat transfer to minimize the loss of gas energy branching through the gas vent.

On other hand, the effect of the control parameters depending on the geometrical characteristics of the gas unit cannot be ignored. These parameters are: area of gas vent, changing the initial volume of gas chamber, and controlling the outlet of gases from the gas chamber [7].

\section{Factors Affecting the Performance of Gas Unit}

The parameters affecting the performance of gas unit can be studied based on the following factors; which are divided into two groups as:

(i) Group A: The parameters affecting the efficiency of Gas unit are:

a - Minimum diameter of gas vent; $\left(d_{0}\right)$

b - Initial volume of gas chamber; $\left(\mathrm{W}_{\mathrm{o}}\right)$

c - Diametric clearance between piston and the cylinder; $\left(\Delta \mathrm{S}_{\mathrm{p}}\right)$

$\mathrm{d}$ - Area of piston head; $\left(\mathrm{S}_{\mathrm{p}}\right)$

(ii) Group B: The parameters affecting the momentum of gases are:

a -Position of gas vent with respect to the barrel bore

b -Mass of moving parts; (MRP)

c - Conditions of heat transfer

According to the work of Prof. Dr. Mamontove [7, 8], he introduced an analytical relations that correlates the change of gas pressure inside the gas cylinder with time.

$$
p_{k}=p_{k m} \cdot z \cdot e^{1-z}=p_{k m} \cdot e \cdot z \cdot e^{-z}
$$

where $P_{k}$ is the pressure of gases inside the gas chamber, $P_{k m}$ is the maximum pressure inside the gas chamber, $\mathrm{z}$ is the dimensionless time ratio $z=t / t_{m}, \mathrm{t}$ is the time variable inside gas unit, and $t_{m}$ is the time duration till the pressure reaches its maximum value in gas unit.

$$
p_{k}=\frac{p_{k m} \cdot e \cdot t}{t_{m}} \cdot e^{--\frac{t}{t m}}
$$

Knowing the pressure time relation inside the gas unit, $P_{k}(t)$, it is possible to determine the important parameters $\left(P_{k m}, t_{m}, t_{k}\right)$, where $t_{k}$ is the time corresponding to the end of action of gases.

Figure 4 shows the pressure variation against the relative time of gases expansion inside and outside the barrel, while the branching gases diagram $P_{k}(t)$ shows the moment and position before which the gas unit opening should not be located. 


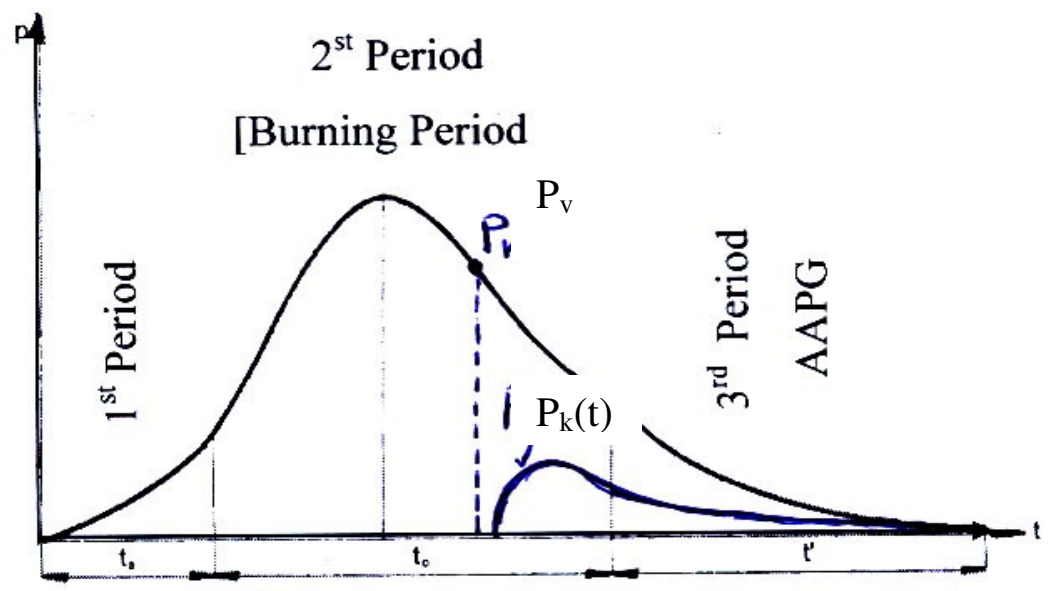

Fig. 4. Schematics diagram of gas pressure-time in barrel bore and gas unit.

As will be discussed later; knowing any two parameters is sufficient to determine the other missing parameters. In the following, a set of functions have been listed forming a set of empirical formulae which help in solution of the above task inside the gas chamber. In addition, these empirical formulae are used for determining all required motion parameters.

\section{GASES PRESSURES VARIATION INSIDE THE GAS UNIT $\left(\mathbf{P}_{\mathrm{k}}(\mathrm{t})\right)$}

Applying Eqn. (1), the pressure variation inside the gas unit is represented by:

$$
p_{k}=p_{k m} \cdot e \cdot \phi_{1}(z), \phi_{1}(z)=z e^{-z}
$$

where $\phi_{1}(z)$ is the Mamontove's empirical function.

Consequently; the equation of motion of moving parts has the form:

$$
M \frac{d V}{d t}=\left(p_{k}-p_{a t m}\right) S_{p}-R=P_{k} S_{p}-\left(R+P_{a t n} S_{p}\right)
$$

where $S_{p}$ is the area of piston head, $M=M_{R P}$ is the mass of weapon moving parts, and $R$ external resisting forces to the moving parts. The last term in Eqn. (4) vanishes due to its small value if compared with the pressure force component inside the gas unit $\left(P_{k} S_{p}\right)$.

\section{VELOCITY OF RECOILING PARTS $(V(t))$}

The specification of variables in Eqn. (4) leads to the expression used for determining the velocity of recoiling parts as: 


$$
\begin{aligned}
& d V=\frac{S_{p} p_{k m} \cdot e}{M} z \cdot e^{-z d t} \\
& d V=\frac{S_{p} p_{k m} \cdot e \cdot t_{m}}{M} z \cdot e^{-z} d z
\end{aligned}
$$

The constant term is marked by the term "B", where $B=\frac{S_{p} \cdot P_{k m} \cdot e \cdot t_{m}}{M}$, and assuming that the integral of $z e^{-z} d z=\Phi_{2}(z)$ then the integration of Eqn. (5)b results in:

$$
V(z)=V_{o} \cdot B \cdot \phi_{2}(z)
$$

The function $\phi_{2}(\mathbf{z})$ can be expressed mathematically by:

$$
\phi_{2}(z)=1-(1+z) \cdot e^{-z}
$$

By applying the initial conditions at $t=0, V_{0}=0$ then the velocity of recoiling parts is expressed by:

$$
V(z)=B \cdot \phi_{2}(z)
$$

\section{DISPLACEMENT OF RECOILING PARTS $(\mathrm{X}(\mathrm{t}))$}

The displacement of moving parts can then be easily determined by integrating equation 6 results the recoiling parts displacement relation:

$$
\begin{gathered}
X=X_{0}+V_{0} . t+\int_{0}^{t} B\left[1-e^{-z}(1+z)\right] d t \\
X(z)=X_{o}+V_{o} . t+B . \Phi_{3}(z)
\end{gathered}
$$

where

$$
\phi_{3}=\int_{0}^{z}\left[1-(1+z) \cdot e^{-z}\right] d z=(z-2)+(z+2) \cdot e^{-z}
$$

By applying the initial conditions: At: $t=0, X_{0}=0$ and $V_{0}=0$, the displacement of recoiling parts is:

$$
\mathrm{X}=\mathrm{B} \cdot \mathrm{t}_{\mathrm{m}} \cdot \phi_{3}(\mathrm{z})
$$

\section{DETERMINATION OF THE COMPLETE IMPULSE OF GASES $i_{k}(t)$}

For determination of specific impulse of gas unit; the following empirical formula [7] is used: 


$$
i_{k}=i_{0} \cdot \eta_{k}
$$

where $i_{0}$ is the specific impulse of gases in the barrel bore from the vent moment till the end of discharge of gases.

$$
i_{0}=\frac{p_{v}+p_{z}}{2} t_{v}+\frac{p_{z}}{A}
$$

where $(A)$ is the coefficient of additional action of gases [8].

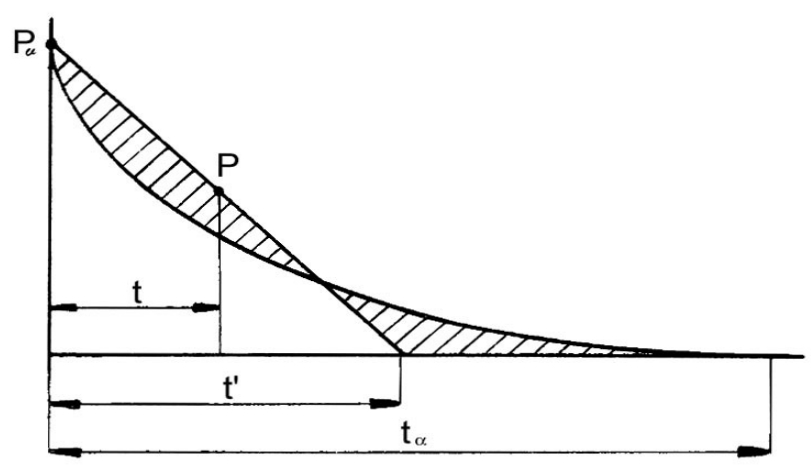

Fig. 5. Simplified scheme of gas impulse at branching point.

In order to simplify the calculations of the impulse of gases; Mamontove has assumed that the exponential form of gases escaping from barrel can be substituted by a straight line where $\left(t=0.5 t_{k}\right)$ as shown in Fig. 5 , providing that the area under the exponential curve in both cases are equal. While the integration of the pressure expressed in equation (3) representing this area under the exponential curve $P_{k}(t)$, which in turn represents also the impulse of gases at a certain time:

$$
\begin{aligned}
& i_{k}=\int_{0}^{t} p_{k} d t=\int_{0}^{t} p_{k m} \cdot e \cdot z \cdot e^{-z} d t=\int_{0}^{z_{k}} p_{k m} \cdot e \cdot z \cdot t_{m} \cdot e^{-z} d z \\
& i_{k}=P_{k m} \cdot e \cdot t_{m} \cdot\left[1-\frac{1+z_{k}}{e^{z k}}\right]
\end{aligned}
$$

Knowing that the value of time taken until the end of discharge of gases from the gas unit is denoted by $t_{k}$ \{usually it is corresponding to the value of $z_{k}$ which varies between $(7: 10)\}[7,8]$. Providing that the second term between brackets in the above relation vanishes due to its relatively small value; the total impulse $\left(i_{k}\right)$ becomes:

$$
i_{k}=p_{k m} \cdot e \cdot t_{m} .
$$

In order to calculate the total time of motion of recoiling parts, $t_{k}$ which is the time corresponding to the end of action of gases inside the gas chamber, multiplying both sides of Eqn. (3) by $t_{k}$ and substituting by $P_{k}=\left(i_{k} / t_{m}\right) \cdot z \cdot e^{-z}$, then the time $t_{k}$ is calculated using the following equation: 


$$
t_{k}=\frac{i_{k}}{p_{a t m}} \cdot z_{k}^{2} \cdot e^{-z_{k}}=\frac{i_{k}}{p_{a t m}} \cdot \phi_{4}(z) .
$$

where $\phi_{4}(\mathrm{z})$ represents the value $z_{k}^{2} \cdot e^{-z k}$ obtained from Mamontove's table.

\section{RESULTS OF CALCULATIONS}

The main equations of the mathematical model in which the parameters affecting the performance of gas unit are arranged and considered into a computer program using MathCAD package, this program allows variation of any parameter which are listed in group-A which affects the performance of G.U. The results due to variations of each parameter are collected and thoroughly analyzed in order to extract the conclusion that determine which is the most effective parameter. These conclusions can be used when looking for modifying the performance of firearms in service or when developing new designed weapon generations.

The weapon model used in this study is that of the in service automatic rifle $7.62 \times 39 \mathrm{~mm}$ AK-47. The results are presented as the variation of the characteristic values of $\mathrm{P}-\mathrm{z}, \mathrm{V}-\mathrm{z}, \mathrm{X}-\mathrm{z}$, and $\mathrm{i}_{\mathrm{k}}-\mathrm{z}$; where $\mathrm{z}$ as presented is the normalized time parameter. In order to show the effect of geometrical dimensions of gas unit momentum; the program runs by varying a single parameter while the others are considered without change, see figs $6,7,8$ and 9 hereinafter. Later, the analyses of results show the effect of each parameter on the momentum of gases branching from the barrel.

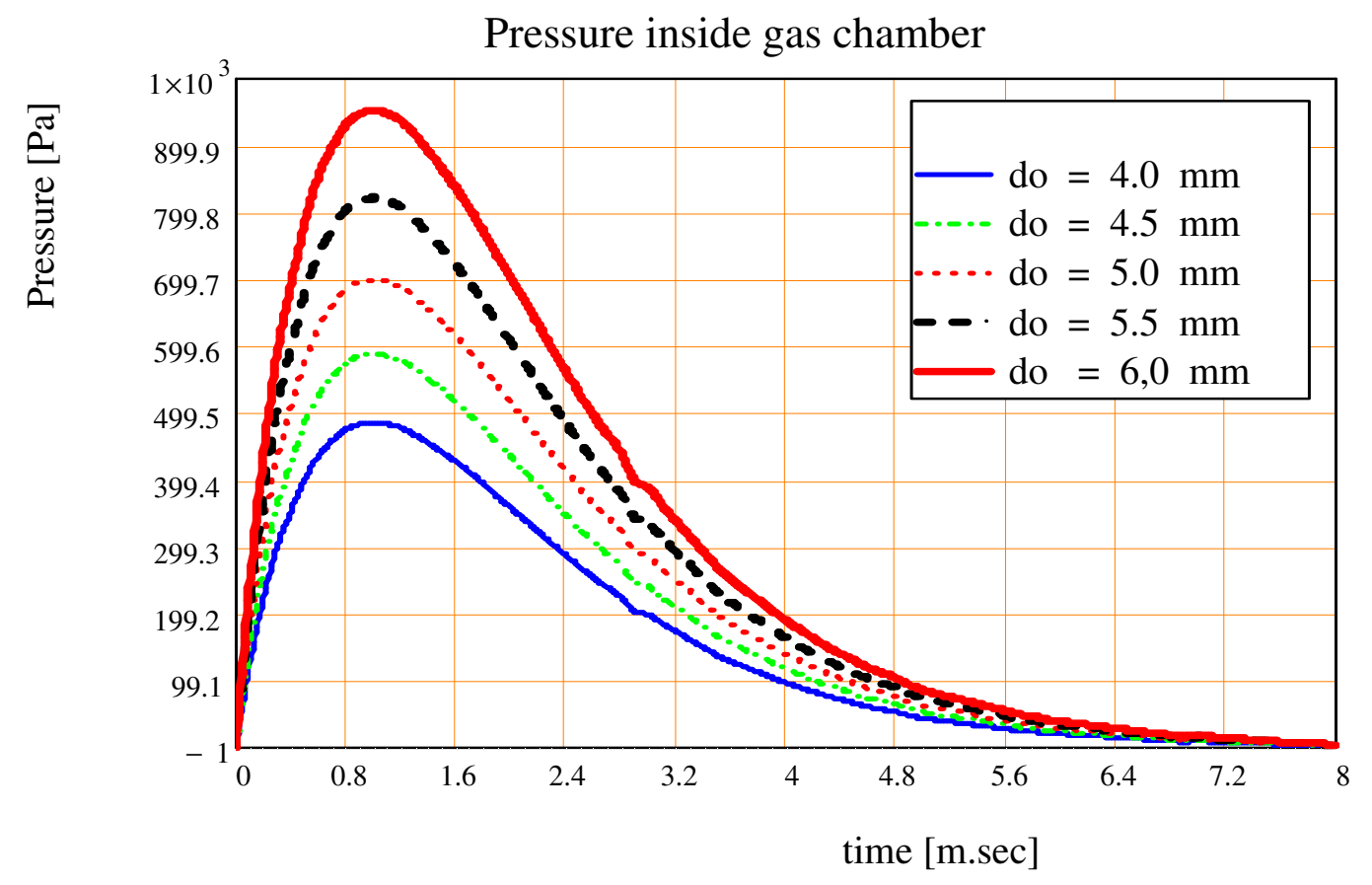

Fig. 6a. Effect of gas vent variation on Pressure inside the Gas Unit. 


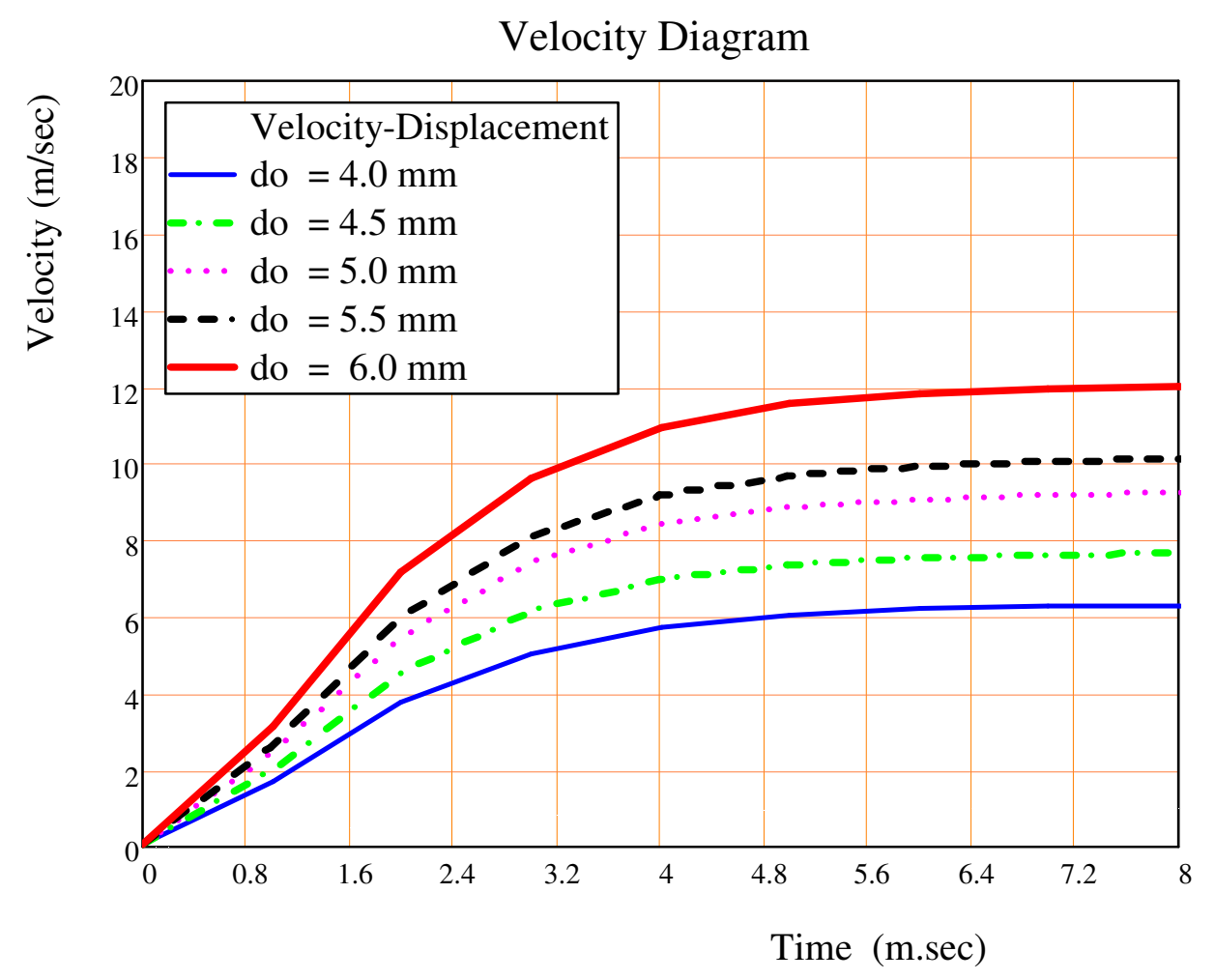

Fig. 6b. Effects of gas vent variation on the velocity of moving Parts.

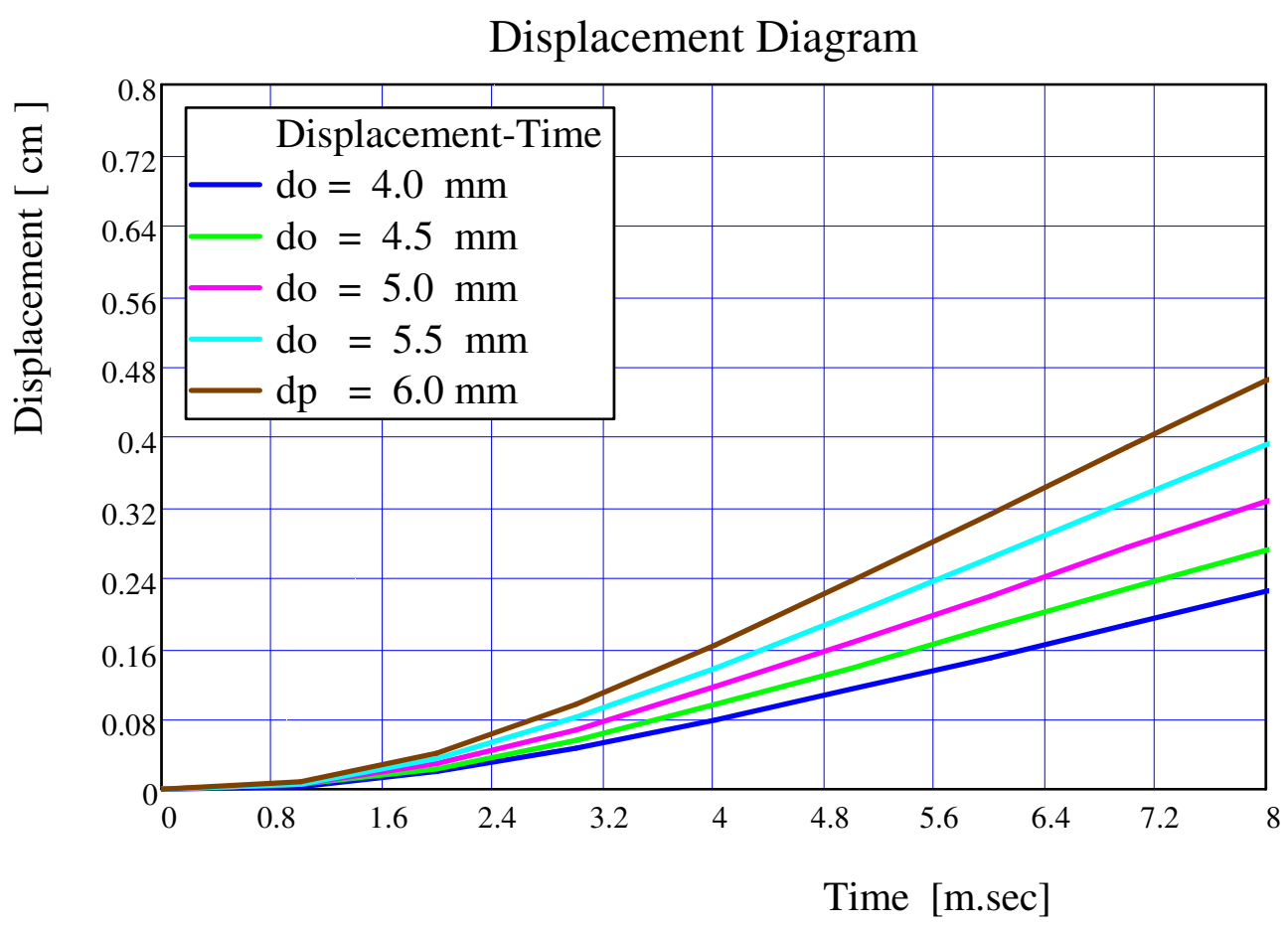

Fig. 6c. Effects of gas vent variation on the displacement of moving parts. 


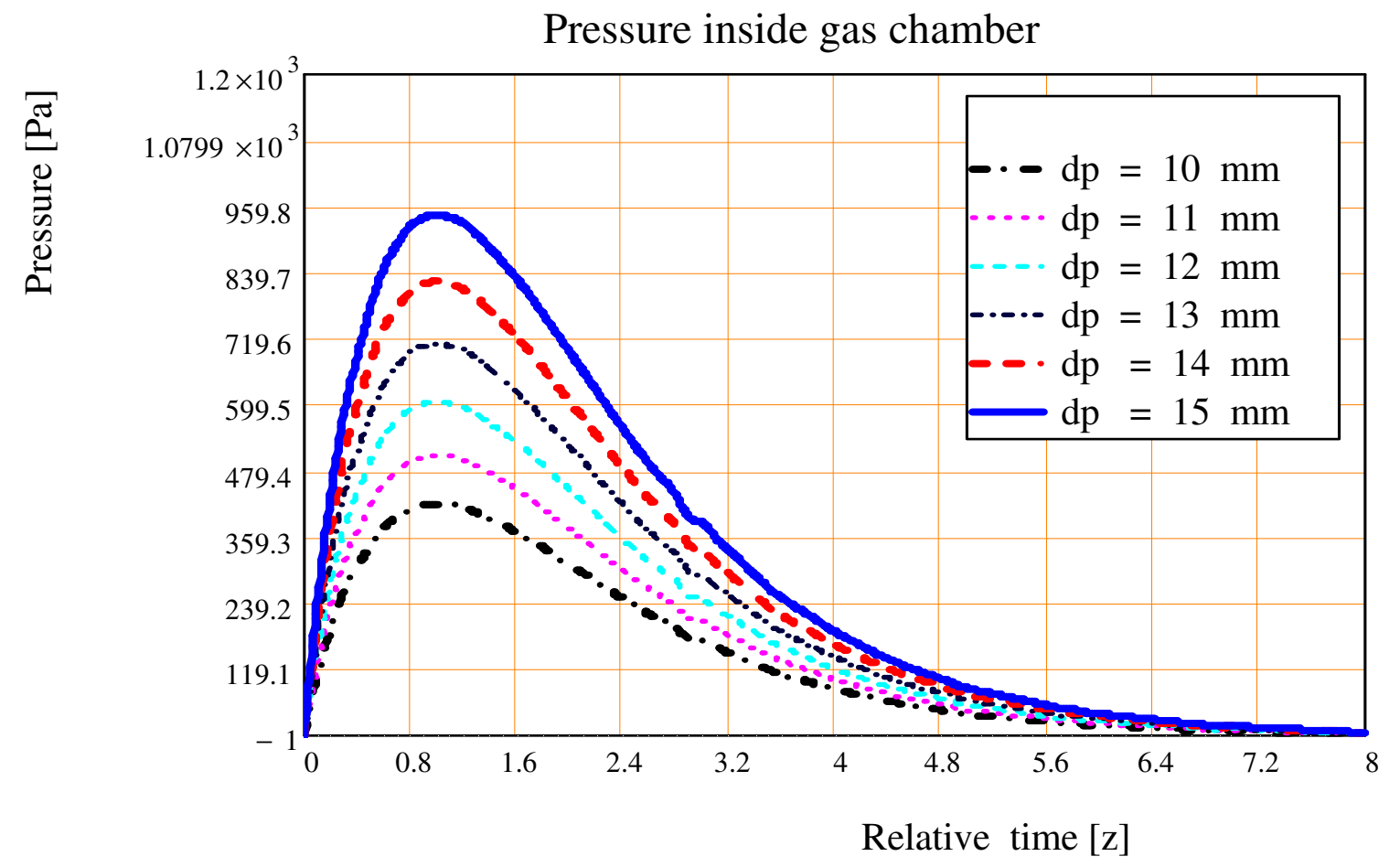

Fig. 7a. Effect of piston diameter variation on Pressure inside the Gas Unit.

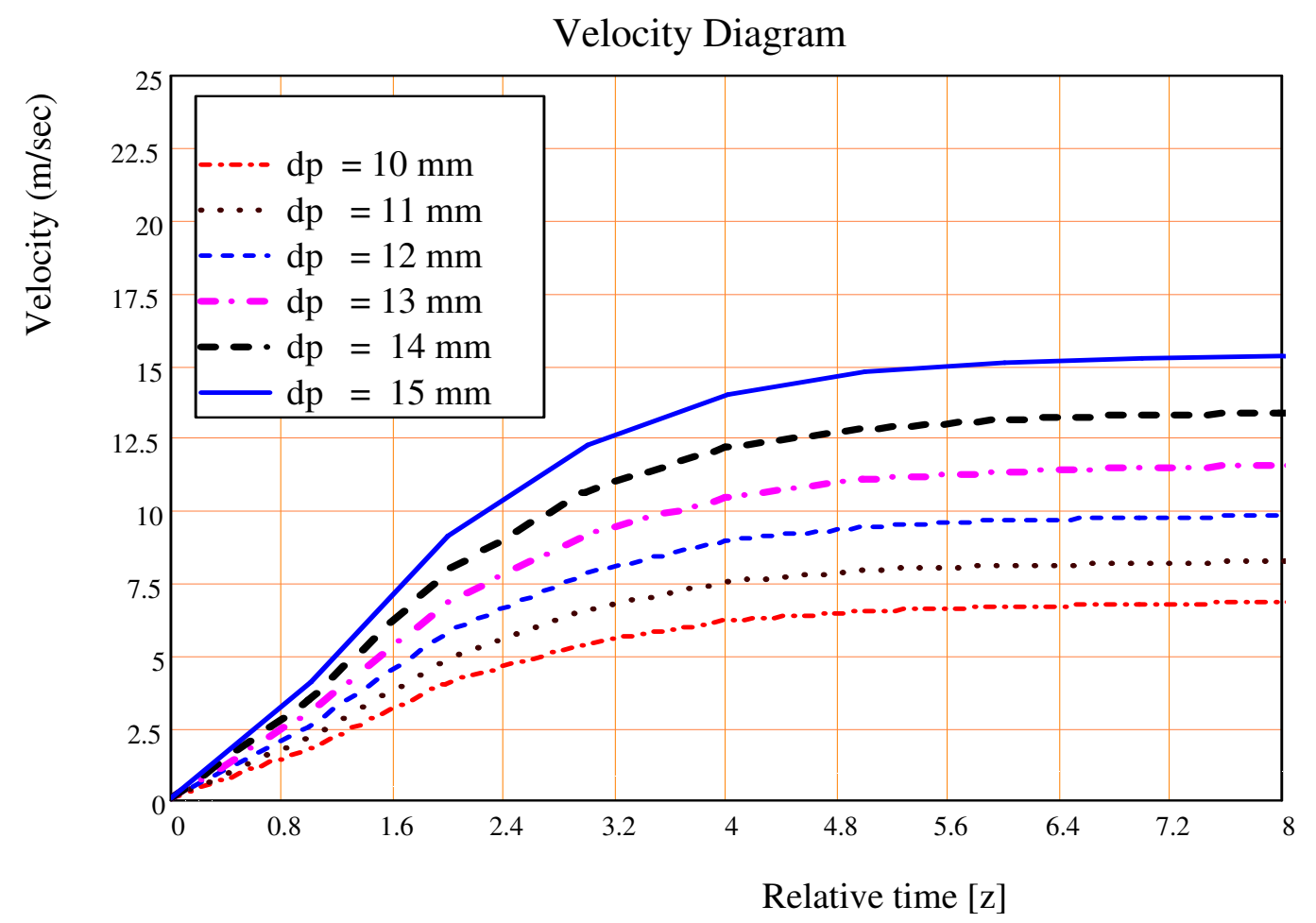

Fig. 7b. Effect of piston diameter variation on velocity of recoiling parts. 


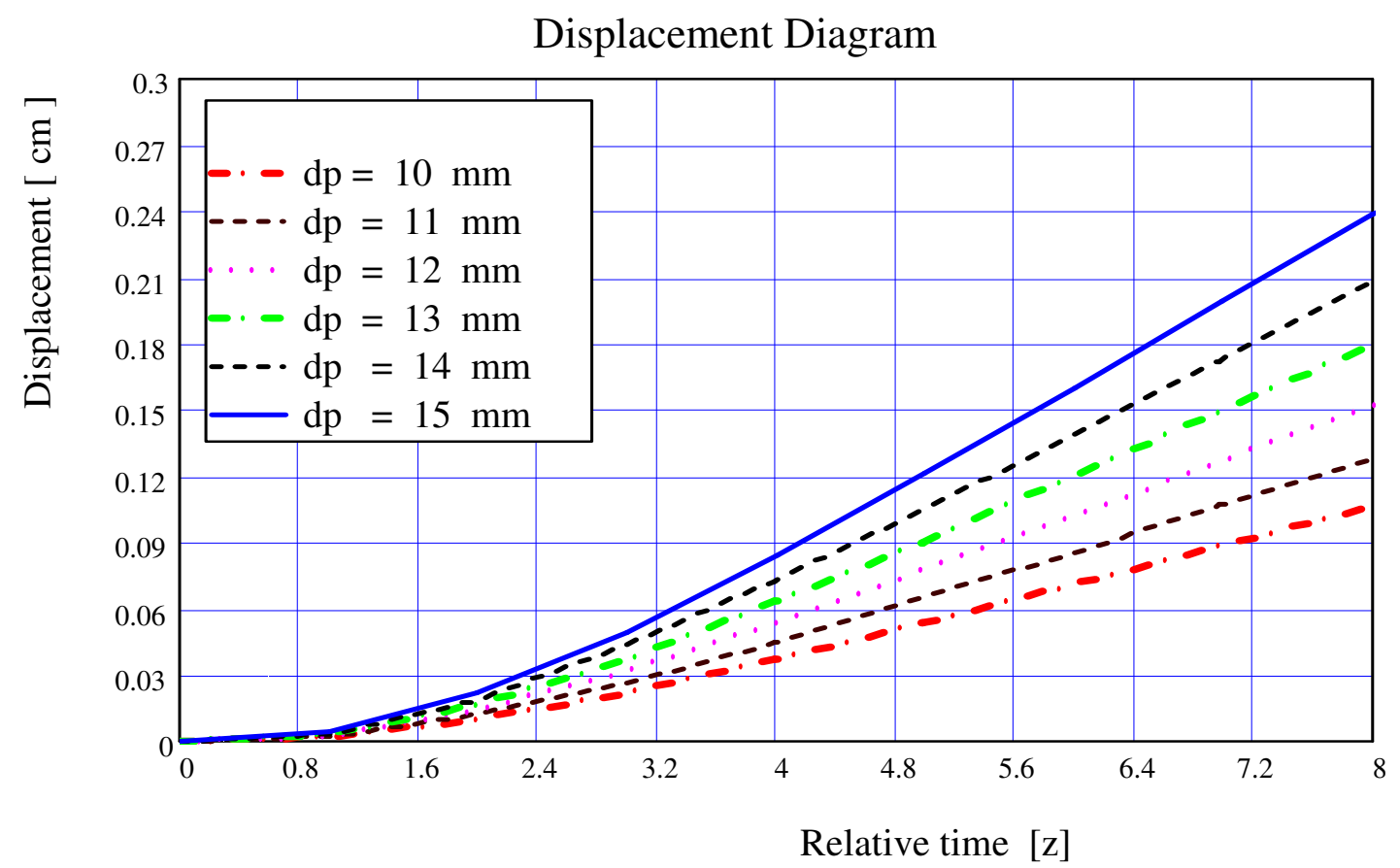

Fig. 7c. Effect of piston diameter variation on displacements of recoiling parts.

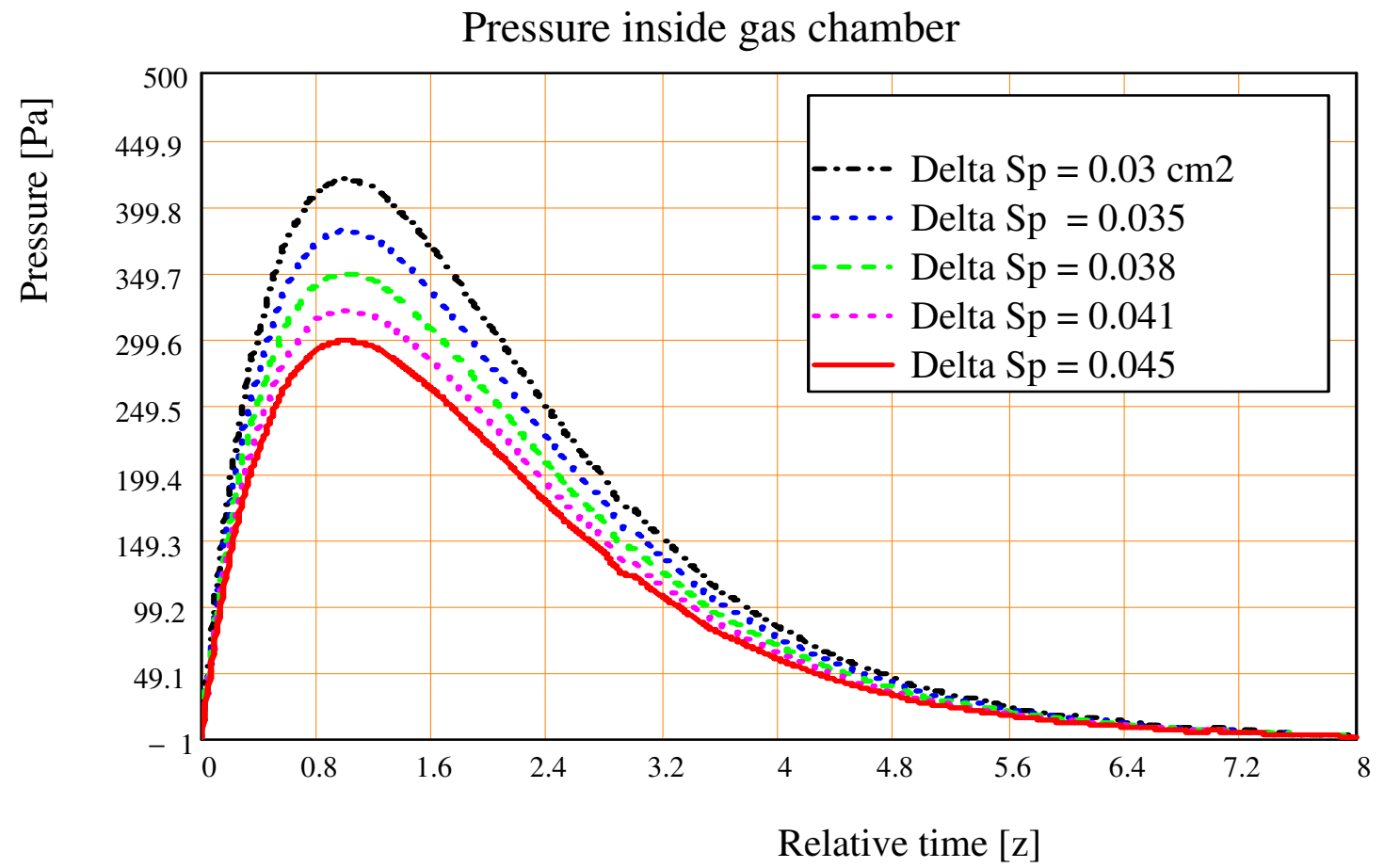

Fig. 8a. Effect of $(\Delta \mathrm{Sp})$ variation on pressure of gases inside the Gas Unit. 


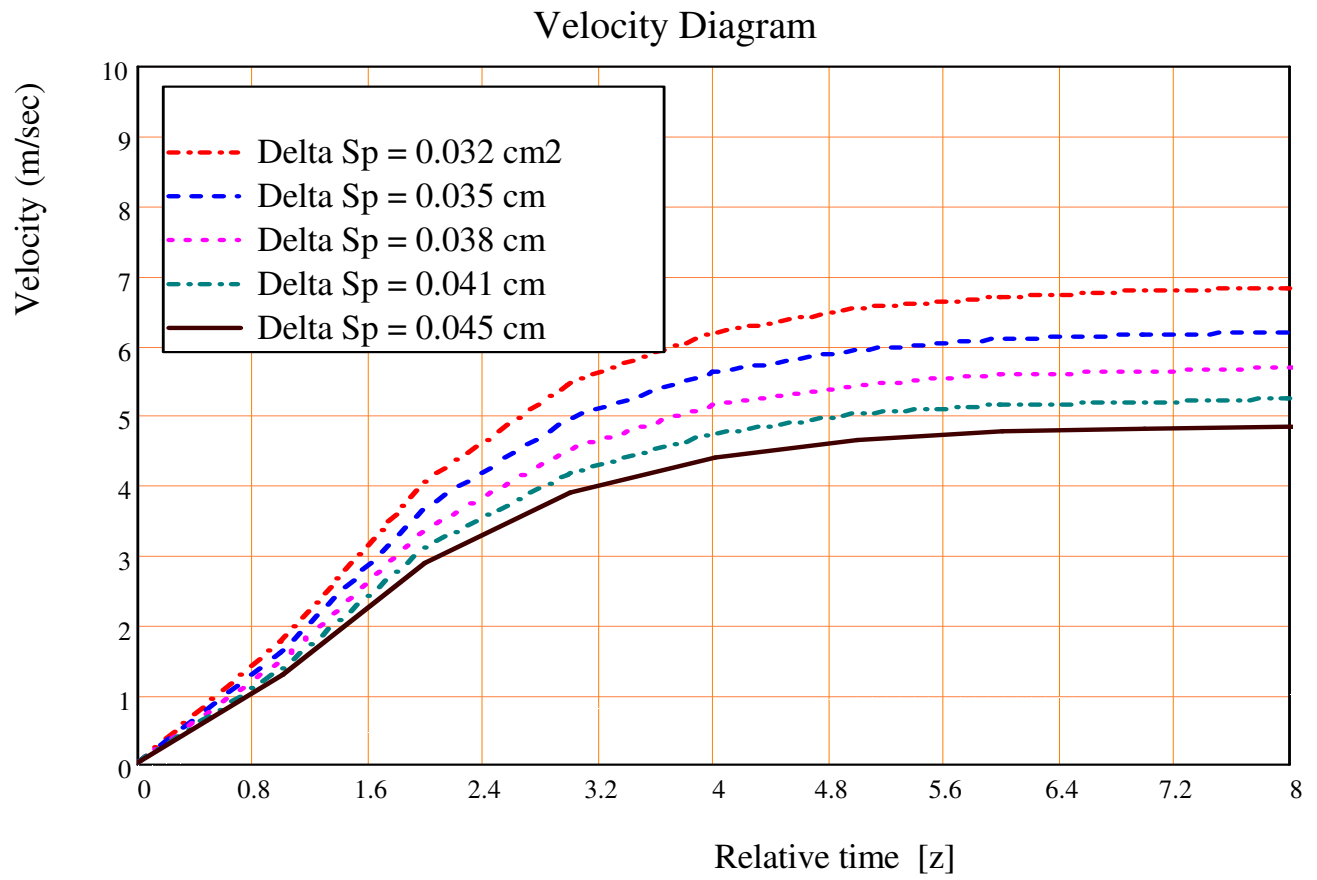

Fig. 8b. Effect of $(\Delta S p)$ variation on Velocity of recoiling parts.

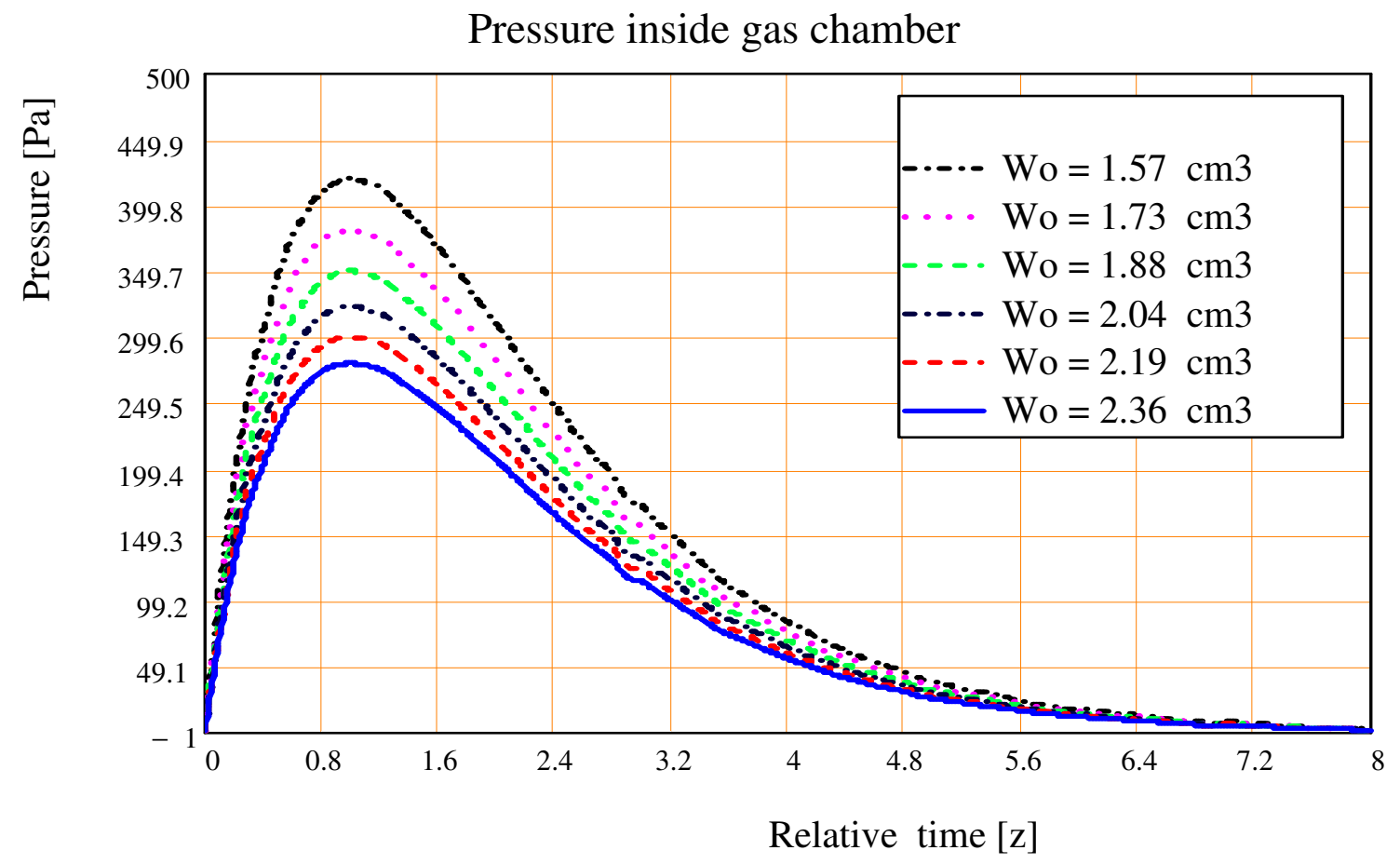

Fig. 9a. Effect of $\left(\mathrm{W}_{\mathrm{o}}\right)$ variation on pressure of gases inside the Gas Unit. 


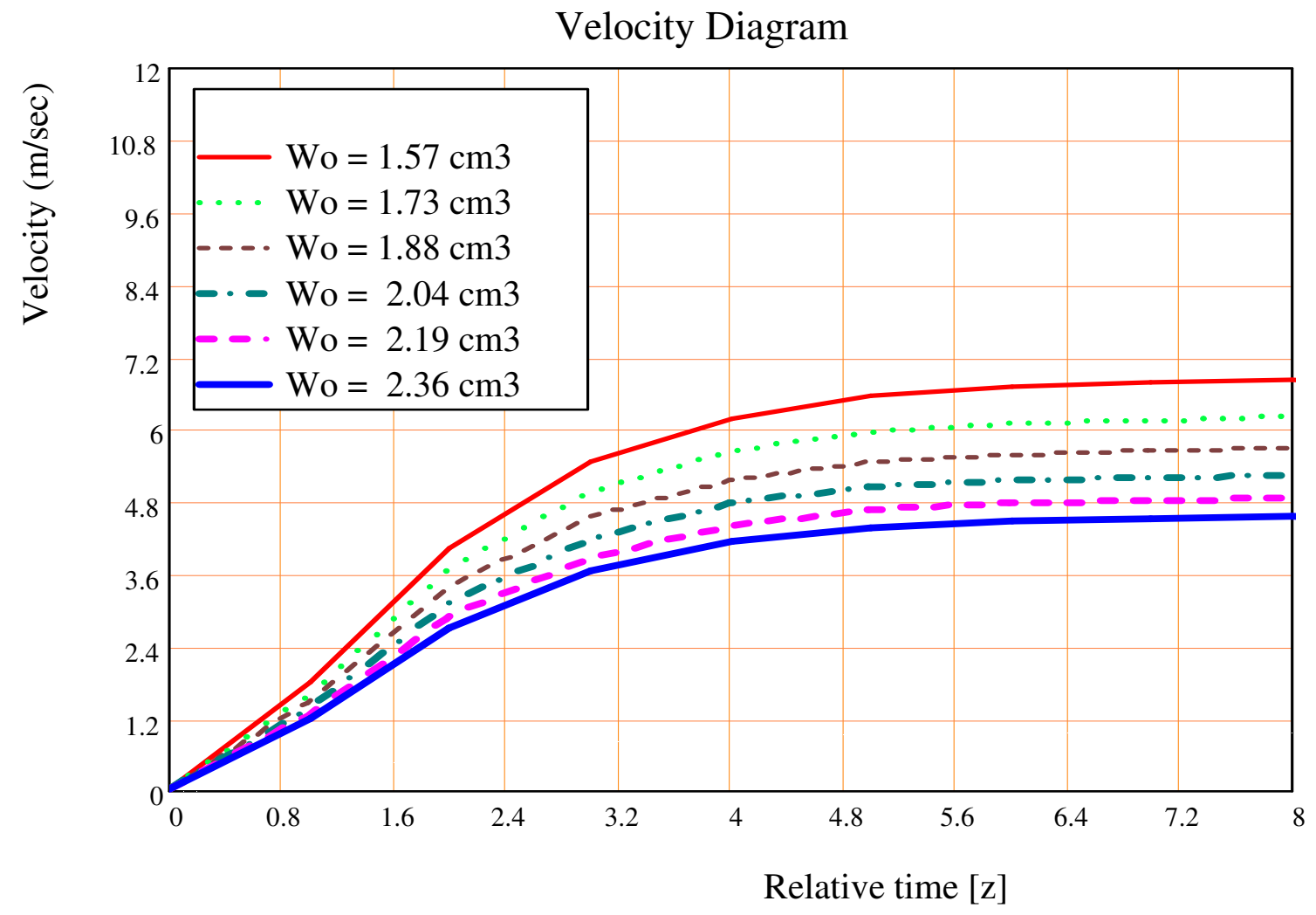

Fig. 9b. Effect of $\left(W_{0}\right)$ variation on Velocity of recoiling parts.

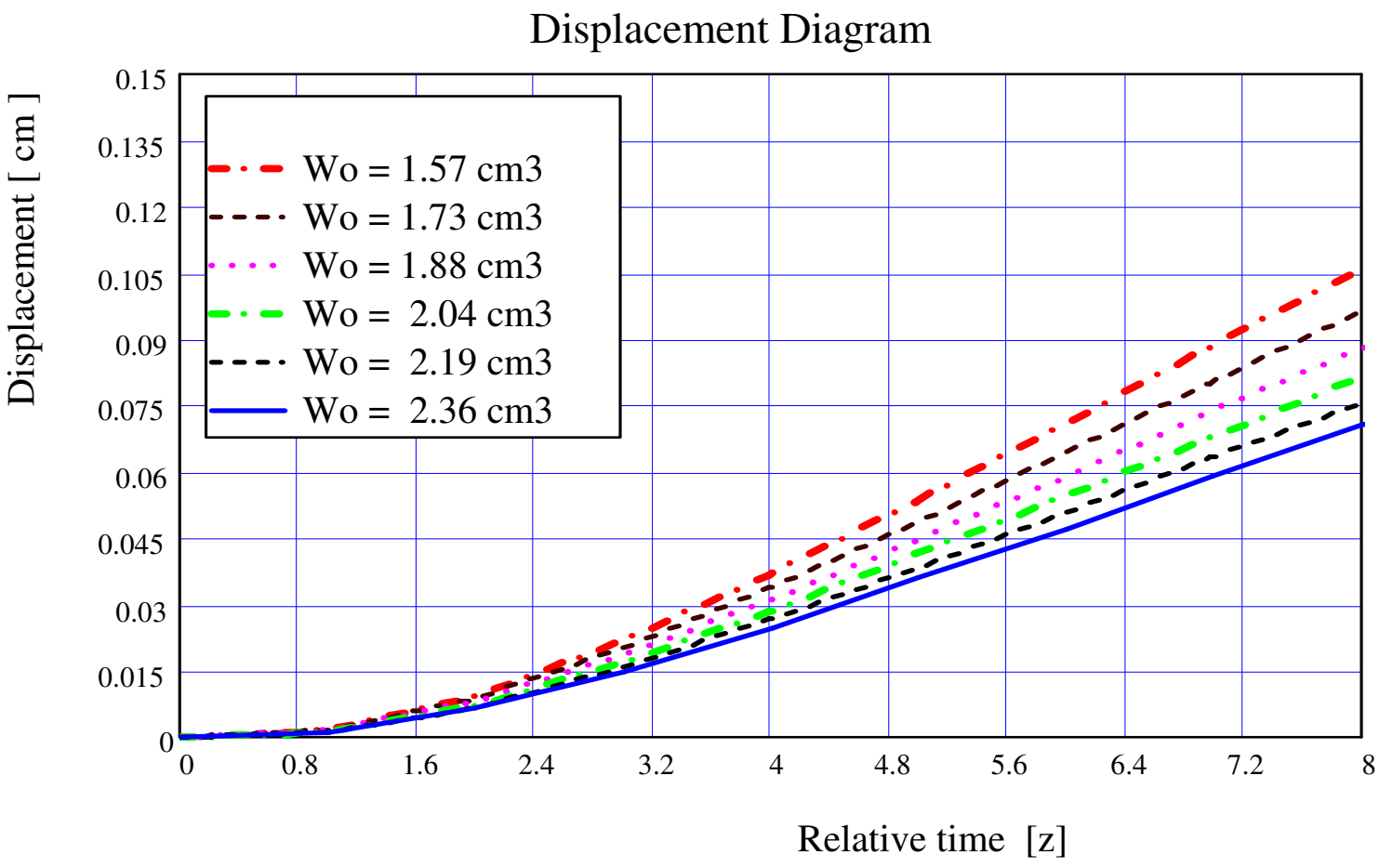

Fig. 9c. Effect of $\left(\mathrm{W}_{\circ}\right)$ variation on the displacements of recoiling parts 
The detailed study of the above obtained results shown in Figs 6, 7, 8, and 9 can be summarized in a statistical diagram shown below in Fig.10. before going in details of their analysis, it is important to list the initial conditions under which the above results have been obtained, in brief:

- All parameters affecting the momentum obtained from the gas unit vary in equal incremented increase from $0 \%$ to $50 \%$ of the nominal value.

- As the momentum of recoiling parts depends mainly on the value of recoil velocity of these parts as the main multiplier, on other hand variation of the mass of recoiling parts represent the undesired term to play with, any increase in mass of recoiling parts directly affects the stability of the whole weapon, the strength requirements of locking surfaces, and the mobility of the whole weapon.

\section{ANALYSIS OF RESULTS}

Upon studying and analyzing the above results, the following important remarks can be extracted:

1- Dependency on the empirical formulae derived by Mamontove has ignored the variation of many geometrical values. In pressure and velocity, Mamontove considered the variation in:
a- Initial pressure.
b- Area of piston head.
c- Time in a form of the dimensionless parameter $z$.
d- The effect of weight of moving parts

2- On other hand, Mamontove ignored the effect of very important parameters that should take more interest for their remarkable effect on the momentum of recoiling parts gained from $\mathrm{GU}$ as [5, 6]:
a- The variation in the control opening of the gas vent.
b- The variation of initial volume and shape of the G.U. chamber.
c- The effect of heat transfer has never considered by any mean.

\section{CONCLUSIONS}

1- The effect of variations in the diameter of gas vent has a tremendous effect on the momentum of gases acting on recoiling parts; it gives optimum usage of branching gases. Since a relative small increase in branching pressure could lead to the target recoil velocity that hold the requirements for recoil energy for the function cycle.

2- Changes by increase in diametric clearance $(\Delta d p)$, as well as the gas unit chamber $\left(W_{o}\right)$ has a negative effect on momentum and leads to undesired reduction to the power of fire. 


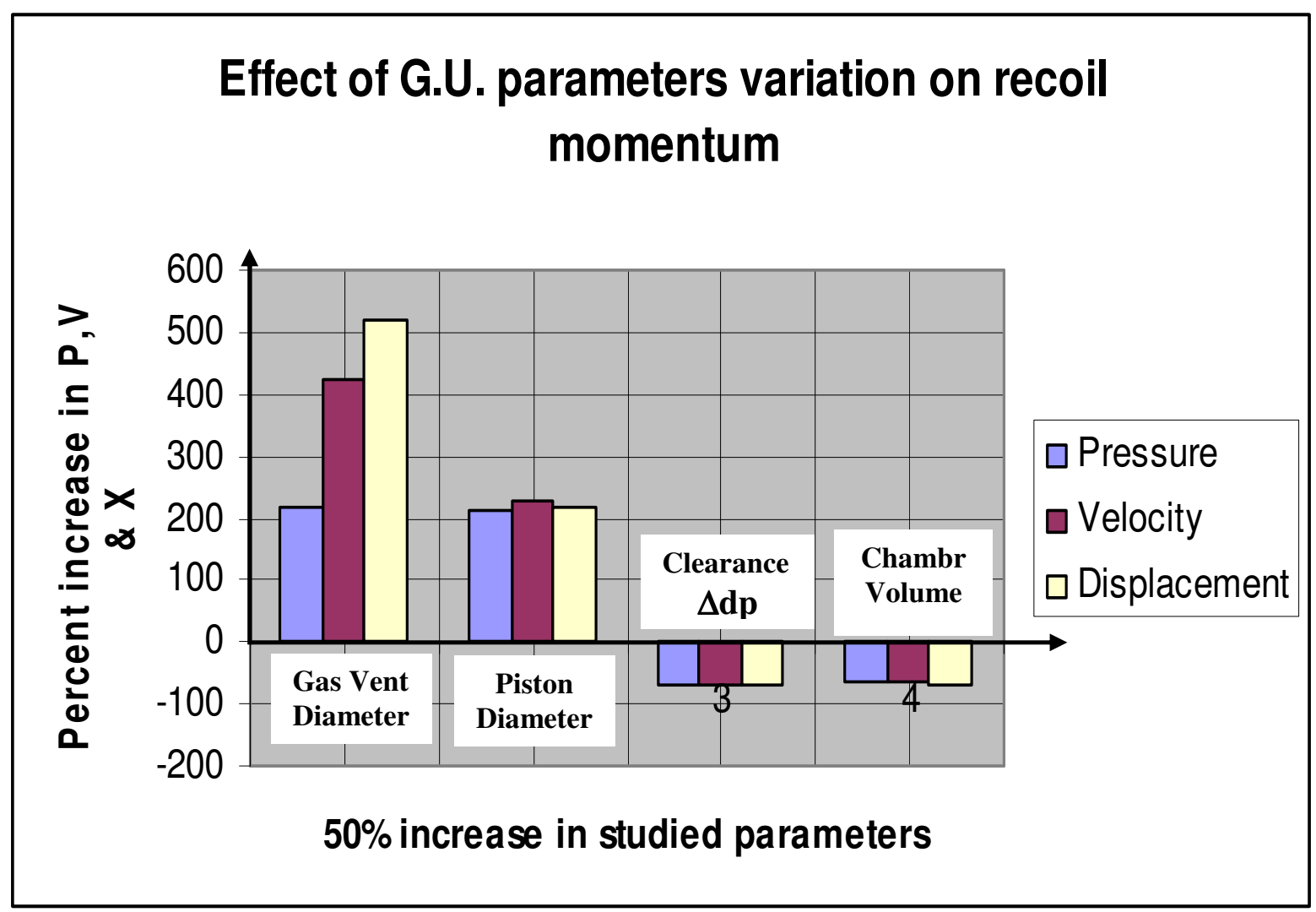

Fig. 10. Statistical histogram showing the relative effect of the change in studied parameters on the recoil momentum of gases.

\section{REFERENCES}

[1] Brochures and service manuals for products of the following brands: a- John Moses Browning (American gun designer).

b- Henri-Gustave Delvigne (French officer and inventor).

c- Henry Deringer (American Gun Smith).

d- Hiram Percy Maxim (American inventor and manufacturer).

e- Patrick Ferguson (Scottish soldier and inventor).

f- William Greener (British inventor and Gun Smith).

j- Michael Kalashinkove (Russian tank soldier and A.S.A Sole Inventor).

[2] F.T. Moore, "Gas Operated Automatic Firearms", patent No. 1,738,501, Connecticut, USA, Dec. (1929).

[3] J. C. Garand, "Gas Regulator for Firearms", Patent No. 2,369,669, Springfield, Mass, USA, Feb. (1945).

[4] G. A. Moore, "Gas Regulating Device Firearms", Patent No. 2,462,119 Springfield, Mass, Secretary of War, USA, Feb. (1949).

[5] "Small Arms" Encyclopedia Britannica. 2010. Encyclopedia Britannica Online. 07 Aug. $2010<$ http://www.britannica.com/EBchecked/topic/549308/smallarm>.

[6] "Small Arms" (2010). In Encyclopedia Britannica. Retrieved August 07, 2010, from Encyclopedia Britannica Online.

[7] Anon, "Theory and Design of Automatic weapons", P.L. No. 40, 41 Part I, MTC, Cairo, Egypt, (1962). 
[8] Anon, "Theory and Design of Automatic weapons", P.L. No. 60, 61 Part II, MTC, Cairo, Egypt, (1962). 